\title{
Research on Aesthetic Characteristics of the Design of Drawing Books for Chinese Children
}

\author{
Li Qing \\ Guangxi Arts University
}

Keywords: Chinese children; design of drawing books; aesthetic characteristics

\begin{abstract}
Design of drawing books is a new mode which emerges in contemporary art education. Researches on aesthetic characteristics of the design of drawing books for children can promote all-round development of contemporary Chinese children. Meanwhile, researches on aesthetic characteristics of the design of drawing books rely on paintings and characters to help children promote their capability of design of drawing books. Furthermore, researches on aesthetic characteristics of the design of drawing books need to cater to underlying analysis on the physical and psychological characteristics of contemporary children. To Chinese children, ideas with traditional cultural colors should be infused into design of drawing books, thereby giving full play to the unique educational function and educational values of researches on aesthetic characteristics of the design of drawing books.
\end{abstract}

\section{Introduction}

As for the educational problem of Chinese children's drawing books in the new era, different painting contents need to be provided for children of different ages, and aesthetic characteristics can be fully presented in the whole design process of drawing content. As the drawings and characters are an important constituent in the whole design process of drawing books, and drawings take up the majority of the while content, in the whole story plot constructive process of the drawing books, main emotions of the drawings are presented in mixed drawings. At present, many drawing contents are designed for Chinese children. The colorful ways, appropriate and abundant plots as well as vivid drawings have won increasingly more Chinese children's favor. Children under Grade Three of primary school are at the specific stage of thinking cognition, which is the best exploration period for imagination and creativity. Therefore, corresponding educational laws and regulations are needed to optimize and regulate design of drawing books. Law of somatopsychic development of Chinese children needs to be abided by, and children should be at the priority place; heuristic thinking should be adopted to stimulate children's dense interest in the drawings, which can provide strong protection for children's better acceptance of drawing books teaching. Children are at the stage of rapid physical and cognition development, so researches on the target-construction and organizational and guiding strategies of the drawing books need to be conducted; children's ability and talent need to be given full play; heuristic education mode should be conformed to during education of drawing books in order to help children establish the awareness of active learning. Therefore, researches on aesthetic characteristics of Chinese children's design of drawing books are of value of times and value of education.

\section{Advantages of Researches on Aesthetic Characteristics of the Design of Drawing Books for Chinese Children}

Children are at the peak time of physical and psychological development. As for learning of drawing books at this stage, children's cognition ability for things in daily life should be made clear. Interest is the only impetus for children's learning at this stage. Then, sufficient exploration needs to be conducted according to children's main characteristics, thereby cultivating children's agile observation ability; meanwhile, children should be encouraged to express their thoughts from corresponding content in drawing books. During this process, children's language ability can also be 
trained. At present, children's drawing books teaching has become an important way for mother tongue language, since it can promote children's learning and development in language. At the same time, children's curiosity and exploration characteristics should be adopted to stimulate their learning of the knowledge in drawing books. Under correct guidance and enlightenment, children can experience happy experiences of learning drawing books. Researches on aesthetic characteristics of the design of drawing books study problems from the perspective of children, and it pays attention to the improvement of children's ability and observation ability, explores children's imagination and creativity, optimizes the design process of Chinese children's drawing books, selects the optimal content, provides children with the best educational materials, thereby providing the optimal drawing book teaching for children.

The design of drawing books influences children's interest in drawing books learning directly. Children's thoughts are specific and vivid in general. In order to further improve children's interest in drawing books, the generation of drawings in drawing books need to be optimized during the design process. No matter it is the design of the content or design of the layout, children's interest needs to be taken into consideration. If designers want children to be interested in drawing books, the most important thing is to cultivate children's reading habit. In addition, children at this stage have limited reading ability, so design principle of simplicity and vividness should be adhered to. Also, some illustration effects should be adopted to further stimulate children's reading desire. From the perspective of children, their thoughts should be paid attention to, and their understanding degree and acceptance degree should be made clear. Therefore, aesthetic characteristics should be applied correctly during the design process of drawing books so that children are willing to read the books. Only in this way can children's interest in drawing books be stimulated sufficiently and children can be fully immersed in the plots.

Most of the children in the new era are under the influence of electronic products and many children are addicted to online games since young, and their parents are unable to teach and control them. To get children to read drawing books can help children get rid of the reliance on electronic products and help build a good reading environment; meanwhile, it can also help build sufficient communication between parents and children. Emotional education is an important teaching content when children are receiving education. Therefore, when they are reading drawing books, appropriate approaches should be adopted to stimulate children's interest in drawing books so that they can love drawing books from the bottom of their heart. Also, under the guidance of drawing books teachers, they can feel happiness truly. Researches on aesthetic characteristics of the design of drawing books can help further give play to the educational function of drawing books, present true values of emotional education and help children experience abundant emotions in drawing books, which are of active influence on the cultivation of children's independent character and quality; also, they can help children treat things in real life with optimistic and active attitude, which is very important for children's healthy growth.

\section{Effective Strategies to Promote the Implementation of Drawing Book Teaching for Chinese Children}

In the new era, talents with creativity are needed in various industries. They need to have agile observation ability to things and give play to their imagination to create huge values to the society. Though children's self-control ability might be poor to some extent, once their imagination is concentrated, more workability might be found. Drawing books can stimulate children's initiative in reading by vivid images, so children need to form good reading habits in daily life. Therefore, design of drawing books need to observe this rule, and it should explore children's creativity and imagination sufficiently. To further develop children's interest in drawing books, the design of drawing books is essentially important. Drawing book teachers need to set children's learning goal as the development of thinking and intelligence according to development characteristics of children. During the observation and thinking process of different drawing books, teachers should apply heuristic method and process the details and omissions in the books. They should enlighten children to profound thinking and analysis for details which express human emotions, propose 
problems of guidance significance according to corresponding content in the books and trigger children's thinking. Suspense processing method can further stimulate children's durability in the reading content and experience the real emotions in books. As for images without real meaning, students can just read and observe simply.

Children are a group of people with poor self-control ability, so methods and strategies should be carefully chosen during the management and education process. Children's interest in things mainly depend on their own hobbies and mental disposition. Therefore, during the design process of drawing books, physical and psychological development rules of children and their mental disposition should be referred to in order to choose the optimal materials. In combination with life realities, they can stimulate children's interest in drawing books. In order to get children be fully immersed in the learning and thinking of drawing books, aesthetic characteristics need to be applied correctly in the design of drawing books. Vivid images and humorous language need to be adopted to stimulate children's activeness and initiative in the thinking of drawing books. Different children have different receptivity and thinking, so their problems during the understanding of drawing books should be summarized continuously. During the design of drawing books, application of aesthetic characteristics should be paid attention. According to learning characteristics of children of different ages, rationality and scientificity are principles that must be observed during design of drawing books, and the most important thing is to present the content in ways that children are interested in, while the key is to consider children's age and understanding degree of the content. Childhood is an important period to cultivate a child's perception and language ability. However, children still need to improve their psychological and cognition ability. Choiceness is a principle that must be observed in design of drawing books. In order to stimulate children's agility to drawing books, some striking pictures and colors should be used for decoration in order to impact children's vision and promote the perception of nervous system, and children's attention to drawing books are increasingly improved during this constant intensification process.

The current scientific and technological standard is very developed, which also drives the rapid development of various industries in the society. In order to cater to the requirements of the rapid development of the society, talent cultivation strategy needs to be implemented well in education. Language is an important way for transportation and thought transformation in the new era, and childhood is an important stage for a child's language development. Therefore, law of somatopsychic development of children needs to be abided by, and the construction of learning environment needs to be valued in children's drawing book design process. Chinese children's acceptance of drawing book education is a new way to cultivate children, and the important teaching target is to cultivate children's good drawing book analysis ability and reading ability. To children, there might be many difficulties and problems for them to understand the drawing book, so teachers are needed in this process to guide students to have a correct understanding the corresponding content in the books. Teachers' interaction with students should be advocated, and teachers' powers are needed to help children understand and learn the books. Aesthetic characteristics should be satisfied for the design of drawing books, and the best contents should be designed for children of different ages to stimulate children's interest in drawing books. Under appropriate conditions, teachers' powers are needed to help children understand drawing books, thereby extending and broadening the books. The design of the drawing books must conform to children's daily life so that children can feel interesting phenomena in life. Suitable contents should be selected for the design of drawing books, but they should not go beyond the scope that children can accept. A good learning environment should be created for children so that children can have a better understanding of the contents in the drawing books, and children should be encouraged to talk about their own opinions about the books they have read. In order to build a better drawing book environment, teachers can prepare many suitable headwear and performance props, so children can give a performance about contents in the books in the way of stage performance. Appropriate guidance should be given according to children's body movements, facial expressions and application of language, and targeted questions should be raised at the right time, thereby triggering children's deep thinking about the books. 


\section{Conclusion}

Researches on aesthetic characteristics of the design of drawing books can further optimize many disadvantages in Chinese children's drawing book teaching and provide children with the best drawing book learning environment. Therefore, people should choose the most appropriate drawing book teaching content, consider problems from children's perspective and give full play to the educational function and real values of drawing book teaching. Researches on aesthetic characteristics of the design of drawing books can help children accept drawing book teaching better, cultivate children's good learning habit and observation ability, explore children's imagination sufficiently and promote successful implementation of Chinese children's drawing book teaching.

\section{References}

[1] Wang Jiarui, Zhou Jing. Research on Aesthetic Characteristics of the Design of Drawing Books for Chinese Children[J]. Research on Preschool Education, 2015, (5).

[2] Liu Xueting. Research on Aesthetic Characteristics of the Design of Drawing Books for Chinese Children[J]. Research on Children Education, 2014, (4).

[3] Zhang Hongwei. Enlightenment and Reflections on Chinese Drawing Books in the New Era [J]. Chinese Teaching, 2016, (8).

[4] Li Wenjie. Educational Strategies on Children's Independent Reading[J]. Research on Preschool Education, 2015, (2).

[5] Ma Wen. Research on Aesthetic Characteristics of the Design of Drawing Books for Chinese Children[J]. Financial Circle (Academic), 2016(11).

[6] Li Wenhua, Research on Aesthetic Characteristics of the Design of Drawing Books for Chinese Children[J]. Education Modernization, 2015(16).

[7] Zhang Jianqiang. Research on Aesthetic Characteristics of the Design of Drawing Books for Chinese Children[J]. Children Education, 2016(13).

[8] Li Jiajia. Research on Aesthetic Characteristics of the Design of Drawing Books for Chinese Children[J]. Modern Children Education, 2015(14).

[9] Liu Sichen. Research on Aesthetic Characteristics of the Design of Drawing Books for Chinese Children[J]. Children Education, 2016, (03). 